\title{
A population-based review of bone morphogenetic protein: associated complication and reoperation rates after lumbar spinal fusion
}

\author{
Jason W. Savage, MD, ${ }^{1}$ Mick P. Kelly, MD, ${ }^{2}$ Scott A. Ellison, MBA, ${ }^{3}$ and Paul A. Anderson, MD² \\ 1Department of Orthopaedic Surgery, Northwestern University Feinberg School of Medicine, Chicago, Illinois; ${ }^{2}$ Department \\ of Orthopedics and Rehabilitation, University of Wisconsin School of Medicine and Public Health, Madison, Wisconsin; and \\ ${ }^{3}$ PearlDiver Technologies, Inc., Warsaw, Indiana
}

\begin{abstract}
OBJECT The authors compared the rates of postoperative adverse events and reoperation of patients who underwent lumbar spinal fusion with bone morphogenetic protein (BMP) to those of patients who underwent lumbar spinal fusion without BMP.

METHODS The authors retrospectively analyzed the PearlDiver Technologies, Inc., database, which contains the Medicare Standard Analytical Files, the Medicare Carrier Files, the PearlDiver Private Payer Database (UnitedHealthcare), and select state all-payer data sets, from 2005 to 2010. They identified patients who underwent lumbar spinal fusion with and without BMP. The ICD-9-CM code 84.52 was used to identify patients who underwent spinal fusion with BMP. ICD9-CM diagnosis codes identified complications that occurred during the initial hospital stay. ICD-9-CM procedural codes were used to identify reoperations within 90 days of the index procedure. The relative risks (and $95 \% \mathrm{Cls}$ ) of BMP use compared with no BMP use (control) were calculated for the association of any complication with BMP use compared with the control.
\end{abstract}

RESULTS Between 2005 and 2010, 460,773 patients who underwent lumbar spinal fusion were identified. BMP was used in $30.7 \%$ of these patients. The overall complication rate in the BMP group was $18.2 \%$ compared with $18.7 \%$ in the control group. The relative risk of BMP use compared with no BMP use was $0.976(95 \% \mathrm{Cl} 0.963-0.989)$, which indicates a significantly lower overall complication rate in the BMP group $(p<0.001)$. In both treatment groups, patients older than 65 years had a statistically significant higher rate of postoperative complications than younger patients $(p<$ 0.001).

CONCLUSIONS In this large-scale institutionalized database study, BMP use did not seem to increase the overall risk of developing a postoperative complication after lumbar spinal fusion surgery.

http://thejns.org/doi/abs/10.3171/2015.7.FOCUS15240

KEY WORDS lumbar spinal fusion; bone morphogenetic protein; complications; epidemiology

$\mathrm{B}$ ONE morphogenetic proteins (BMPs) are potent cytokines that are essential to musculoskeletal development, homeostasis, and repair. The osteoinductive potential of BMP facilitates spinal fusion and negates the potential morbidity associated with harvesting iliac crest bone graft..$^{39}$ The clinical use of recombinant human BMP-2 (rhBMP-2 or Infuse [Medtronic]) was approved by the FDA in 2002 for anterior lumbar interbody fusion with an LT-Cage (Medtronic). ${ }^{11}$ Since its approval, BMP has been widely used off-label for posterolateral spinal fusion, ${ }^{10,13}$ posterior interbody fusion, ${ }^{14,17,28}$ transforaminal lumbar interbody fusion, ${ }^{28}$ anterior cervical fusion, ${ }^{1,22,24}$ and posterior cervical fusion..$^{7,15}$

The authors of several studies have recently criticized the safety of this biological substance. Carragee et al. ${ }^{5}$ published a systematic review on the emerging safety concerns regarding the use of rhBMP-2 in spinal surgery. They concluded that rhBMP-2 is associated with a significantly higher rate of postoperative complications than has been suggested by other peer-reviewed publications,

ABBREVIATIONS $\mathrm{BMP}=$ bone morphogenetic protein $\mathrm{CCl}=$ Charlson Comorbidity Index; rhBMP-2 = recombinant human $\mathrm{BMP}-2 ; \mathrm{RR}=$ relative risk .

SUBMITTED May 11, 2015. ACCEPTED July 9, 2015.

INCLUDE WHEN CITING DOI: 10.3171/2015.7.FOCUS15240. 
including an increased risk of retrograde ejaculation after anterior lumbar interbody fusion, $, 2,6,23$ osteolysis and subsidence, ${ }^{17,19,20,25,26}$ ectopic bone formation and an increased risk of radiculitis, ${ }^{14,16,28}$ infection, ${ }^{27}$ a higher reoperation rate,$^{28}$ and potential risk of developing cancer. ${ }^{12}$

Three population-based studies provided contrary data. ${ }^{4,8,27}$ Both Williams et al. ${ }^{27}$ and Cahill et al. ${ }^{4}$ reported no significant difference in the overall complication rates associated with the use of BMP in posterior cervical, thoracic, or lumbar procedures. However, these authors did report an increased complication rate with the use of BMP in anterior cervical surgery. Deyo et al. ${ }^{8}$ found that in an older population the use of BMP resulted in fewer discharges to nursing homes and no differences in the rate of major complications, reoperations, or mortality.

The purpose of the present study was to compare the incidence of postoperative adverse events and reoperation rates associated with lumbar spinal fusions performed using BMP to those associated with the same procedure performed without BMP.

\section{Methods}

\section{Institutional Database}

We retrospectively analyzed the PearlDiver Technologies, Inc., database, which contains Medicare Standard Analytical Files, the Medicare Carrier Files, the PearlDiver Private Payer Database (UnitedHealthcare), and select state all-payer data sets, from 2005 to 2010. The ICD-9-CM procedural codes that identified patients who underwent a lumbar spinal fusion are listed in Table 1. The ICD-9-CM Code 84.52 was used to identify patients who underwent spinal fusion in which BMP was used. The absence of this code defined the control group. Important covariates reported in the PearlDiver database were sex and age. Age was grouped as younger than 65 or 65 years or older. Each patient was enrolled once. The University of Wisconsin Institutional Review Board provided exemption for this project.

\section{Complications}

ICD-9-CM diagnosis codes identified complications that occurred during the initial hospital stay. Complications were categorized into 1 of 10 groups: respiratory; peripheral vascular; CNS; hematoma; accidental cut, puncture, or hemorrhage during the procedure; complications of the operative wound, including infection; other; CSF leak; deep vein thrombosis; and mechanical complication of an implant or graft (Appendix 1). In addition, we determined the average Charlson Comorbidity Index (CCI) for patients without complications and for patients with 1 or more complications.

\section{Reoperation Rate}

ICD-9-CM procedural codes were used to identify reoperations within 90 days of the index procedure. A list of ICD-9-CM codes commonly associated with reoperations was developed from a database search at the University of Wisconsin (Appendix 2).
TABLE 1. ICD-9 procedural codes for spinal fusion

\begin{tabular}{cc}
\hline ICD-9 Code & \multicolumn{1}{c}{ Description } \\
\hline 81.04 & Dorsal \& dorsolumbar fusion, anterior technique \\
\hline 81.05 & Dorsal \& dorsolumbar fusion, posterior technique \\
\hline 81.06 & $\begin{array}{c}\text { Lumbar \& lumbosacral fusion of the anterior column, } \\
\text { anterior technique }\end{array}$ \\
\hline 81.07 & $\begin{array}{c}\text { Lumbar \& lumbosacral fusion of the posterior column, } \\
\text { posterior technique }\end{array}$ \\
\hline 81.08 & $\begin{array}{c}\text { Lumbar \& lumbosacral fusion of the anterior column, } \\
\text { posterior technique }\end{array}$ \\
\hline 81.36 & $\begin{array}{c}\text { Refusion of lumbar \& lumbosacral spine, anterior } \\
\text { column, anterior technique }\end{array}$ \\
\hline 81.37 & $\begin{array}{c}\text { Refusion of lumbar \& lumbosacral spine, posterior } \\
\text { column, posterior technique }\end{array}$ \\
\hline 84.52 & $\begin{array}{c}\text { Refusion of lumbar \& lumbosacral spine, anterior } \\
\text { column, posterior technique }\end{array}$ \\
\hline
\end{tabular}

\section{Statistical Analysis}

The relative risks (RR) and 95\% confidence intervals of BMP use compared with no BMP use (control) were calculated for the association of any complication with BMP usage compared with the control. An unpaired t-test calculation was used to compare the average $\mathrm{CCI}$ between patients who underwent spinal fusion with BMP and those who underwent the surgery without BMP. Statistical significance was defined as a Type I error $(\alpha)$ of less than 0.05 .

\section{Results}

\section{Patient Cohorts}

Between 2005 and 2010, 460,773 patients who underwent a lumbar spinal fusion were identified (Table 2). BMP was used in $30.7 \%$ of the patients. Females composed $62.3 \%$ of the BMP group and $60.5 \%$ of the control group. The use of BMP was significantly higher in female patients than in male patients (31.3\% vs $29.8 \%$, respectively; $\mathrm{p}<0.001)$. There was no difference in the utilization of BMP between the $<65$ - and $\geq 65$-year age groups $(30.6 \%$ vs $30.7 \%$, respectively; $\mathrm{p}=0.42$ ).

\section{Overall Complication Rate}

The overall complication rate in the BMP group was

TABLE 2. Patient demographics

\begin{tabular}{cccc}
\hline & & \multicolumn{2}{c}{$\%$ of Patients } \\
\cline { 3 - 4 } Demographic & No. of Patients & BMP Group & Control Group \\
\hline Total no. of ops & 460,773 & 30.7 & 69.3 \\
\hline Age (yrs) & & & \\
\hline$<65$ & 149,952 & 32.5 & 32.6 \\
\hline$\geq 65$ & 310,821 & 67.5 & 67.4 \\
\hline Sex & & & \\
\hline Male & 179,523 & 37.7 & 39.5 \\
\hline Female & 281,250 & 62.3 & 60.5 \\
\hline
\end{tabular}


TABLE 3. Complication rates after spinal fusion with or without BMP

\begin{tabular}{lccccc}
\hline \multicolumn{1}{c}{ Patient Population } & No. of Patients & BMP Group (\%) & Control Group (\%) & $\mathrm{p}$ Value* & RR of Complication (95\% Cl)† \\
\hline Overall complications & 460,773 & 18.2 & 18.7 & $<0.001$ & $0.976(0.963-0.989)$ \\
\hline$<65$ yrs & 149,952 & 17.6 & 16.9 & 0.001 & $1.042(1.017-1.067)$ \\
\hline$\geq 65$ yrs & 310,821 & 18.6 & 19.6 & $<0.001$ & $0.950(0.935-0.965)$ \\
\hline Male & 179,523 & 18.1 & 18.5 & 0.015 & $0.974(0.953-0.995)$ \\
\hline Female & 281,250 & 18.4 & 18.8 & 0.005 & $0.976(0.960-0.993)$ \\
\hline * Determined using the chi-square test. & & & & & \\
$\dagger$ & & & & &
\end{tabular}

$18.2 \%$ compared with $18.7 \%$ in the control group (Table 3 ). The RR of BMP use compared with no BMP use was 0.976 (CI 0.963-0.989), which indicates a significantly lower overall complication rate in the BMP group $(\mathrm{p}<0.001)$.

\section{Effect of Age}

In both treatment groups, patients older than 65 years had a significantly higher rate of postoperative complications than the younger patients $(\mathrm{p}<0.001)$ (Table 3$)$. In patients younger than 65 years, the RR of developing a complication with the use of BMP was 1.042 (CI 1.0171.067 ), whereas in the patients $\geq 65$ years old, the opposite was true (RR 0.950 [CI 0.935-0.065]).

\section{Effect of Sex}

For both males and females, the complication rates were lower in the BMP group than in the control group (Table 3). The RRs of BMP use compared with no BMP use were 0.974 (CI 0.953-0.995) in males and 0.976 (CI 0.960-0.993) in females. The RR was significantly lower in the BMP group for females but not for males $(\mathrm{p}<0.001)$.

\section{Charlson Comorbidity Index}

Patients with 1 or more complications had a higher CCI than patients in all subgroups who had no complications (Table 4). In addition, patients who underwent spinal fusion without BMP had a higher CCI than the patients in all subgroups who received BMP, except for female patients without a complication.

\section{Reoperations Rates}

The overall 90-day reoperation rates were $1.84 \%$ in the control group and $2.03 \%$ in the BMP group (Table 5). The RR of reoperation was 1.108 (CI 1.060-1.158), which was significant and indicates a lower rate in the control group. In both the control and BMP groups, patients younger than 65 years were more likely to have a reoperation than patients older than 65 years $(\mathrm{p}<0.001)$.

\section{Complication Types}

The most common complications in both groups were mechanical complications with the implant or graft, hematoma, and wound infection. BMP was associated with a significantly decreased risk of the following complication types: peripheral vascular; CNS; hematoma; accidental cut, puncture, or hemorrhage during the procedure; complications of the operative wound, including infection; CSF leak; deep vein thrombosis; and cardiac. However, BMP was associated with a significantly higher risk of a mechanical complication of the implant or graft and "other" complications, which include unspecified complications and abnormal reactions in the patient. The RRs of developing a specific complication with BMP compared with no BMP are summarized in Table 6 and Fig. 1. The risk of developing a postoperative wound complication in the BMP group was significantly lower than that in the control group (RR 0.808 [CI 0.783-0.835]).

\section{Discussion}

The clinical use of BMP has increased significantly over

TABLE 4. CCI data for the BMP and control groups and the effect of BMP on overall complication rates

\begin{tabular}{|c|c|c|c|c|c|c|c|c|}
\hline \multirow[b]{2}{*}{ Complications } & \multicolumn{3}{|c|}{ BMP Group } & \multicolumn{3}{|c|}{ Control Group } & \multirow[b]{2}{*}{$p$ Value } & \multirow[b]{2}{*}{ Difference $(95 \% \mathrm{Cl})$} \\
\hline & No. & $\mathrm{CCl}$ & SD & No. & $\mathrm{CCl}$ & SD & & \\
\hline \multicolumn{9}{|l|}{ None } \\
\hline Overall & 115,698 & 5.42 & 3.98 & 259,540 & 5.50 & 4.73 & $<0.001$ & $-0.080(-0.111$ to -0.049$)$ \\
\hline Male & 43,779 & 5.58 & 4.30 & 102,742 & 5.73 & 5.21 & $<0.001$ & $-0.150(-0.206$ to -0.094$)$ \\
\hline Female & 71,919 & 5.38 & 3.76 & 156,798 & 5.40 & 4.38 & 0.290 & $-0.020(-0.057$ to 0.017$)$ \\
\hline$<65$ yrs & 37,862 & 3.70 & 3.92 & 86,463 & 3.49 & 4.58 & $<0.001$ & 0.210 (0.157 to 0.263$)$ \\
\hline$\geq 65$ yrs & 77,836 & 6.31 & 3.71 & 173,077 & 6.55 & 4.47 & $<0.001$ & $-0.240(-0.276$ to -0.204$)$ \\
\hline \multicolumn{9}{|l|}{$\geq 1$} \\
\hline Overall & 25,825 & 6.12 & 4.37 & 59,710 & 6.46 & 5.47 & $<0.001$ & $-0.340(-0.416$ to -0.265$)$ \\
\hline Male & 9,636 & 6.35 & 4.76 & 23,366 & 6.89 & 6.07 & $<0.001$ & $-0.540(-0.676$ to -0.404$)$ \\
\hline Female & 16,189 & 6.04 & 4.08 & 36,344 & 6.26 & 5.03 & $<0.001$ & $-0.220(-0.308$ to -0.132$)$ \\
\hline$<65$ yrs & 8,077 & 4.74 & 4.23 & 17,550 & 4.93 & 5.48 & 0.006 & $-0.190(-0.325$ to -0.055$)$ \\
\hline$\geq 65$ yrs & 17,748 & 6.80 & 4.25 & 42,160 & 7.16 & 5.33 & $<0.001$ & $-0.360(-0.449$ to -0.272$)$ \\
\hline
\end{tabular}


TABLE 5. Reoperation rates

\begin{tabular}{lccccc}
\hline Patient Population & No. of Patients & BMP Group (\%) & Control Group (\%) & p Value & RR of Complication (95\% Cl) $\dagger$ \\
\hline Overall reop rate & 460,773 & 2.0 & 1.8 & $<0.001$ & $1.108(1.060-1.158)$ \\
\hline$<65$ yrs & 149,952 & 2.9 & 2.1 & $<0.001$ & $1.419(1.326-1.517)$ \\
\hline$\geq 65$ yrs & 310,821 & 1.6 & 1.7 & 0.013 & $0.928(0.875-0.984)$ \\
\hline * Determined using the chi-square test. & & & & \\
+ RR for BMP use compared to no BMP use. & & &
\end{tabular}

the last decade, and BMP is currently used in up to $30 \%$ of lumbar spinal fusion procedures. ${ }^{4}$ The safety profile of this biological agent has been questioned, and a study by Carragee et al. ${ }^{5}$ aptly heightened our interest in examining the complication rate associated with the use of BMP. Until recently, most of the literature was based on nonrandomized controlled trials and small retrospective case series; therefore, the data have been limited.

In this study, we used several databases, including all Medicare and some private-payer data that identified patients who underwent lumbar spinal fusion with and those had the surgery without BMP. The use of BMP was $30.7 \%$, which is consistent with other studies. ${ }^{4,8,27}$ Our results show that the overall complication rates in the BMP and control groups (18.2\% vs $18.7 \%$ ) were clinically similar. These results are similar to those of Cahill et al. ${ }^{4}$ and Deyo et al., ${ }^{8}$ who used a similar methodology to compare adverse events, and to those of Williams et al., ${ }^{27}$ who used the Scoliosis Research Society database of self-reported complications. Our absolute rate of adverse events was 2-3 times greater than those in these other reports. We believe that we used a much wider range of ICD-9-CM codes to identify both medical and surgical complications.

In both treatment groups, patients 65 years of age and older had a higher incidence of developing a postoperative complication than patients younger than 65 years. This finding is consistent with recently published data that showed age to be an independent risk factor for developing postoperative complications..$^{21}$ The use of BMP was asso- ciated with an overall lower RR of developing most postoperative complications (Fig. 1), including wound infection and hematoma. The risk of developing a mechanical complication of the implant or graft was slightly higher in the BMP group $(6.62 \%$ vs $5.00 \%$, respectively; $\mathrm{p}<0.001)$. We cannot determine the exact cause of this specific complication. We acknowledge that the statistical significance of this is likely a result of the very large number of patients and that, clinically, BMP does not provide a "protective" effect on developing postoperative complications. Nevertheless, the results of this large population-based analysis support the claim that BMP does not significantly increase the overall risk of postoperative adverse events.

The overall reoperation rate was lower in the control group than in the BMP group (1.8\% vs $2.0 \%$, respectively). We do not have a scientific explanation for this based on our data, but it may be a result of the fact that BMP is often used in more revision and complicated surgical procedures, but this is purely speculative. In the control and BMP groups, patients younger than 65 years were more likely to have a reoperation than patients older than 65 years $(p<0.001)$. The average length of stay after a lumbar spinal fusion with or without BMP was 5 days, and there was no difference in length of stay between the BMP and control groups.

In their study, Cahill et al. ${ }^{4}$ used the Nationwide Inpatient Sample database from 2002 to 2006 to identify complications related to spinal fusion surgeries performed with and those performed without BMP. In reviewing data of

TABLE 6. Overall risks of developing specific complications after lumbar spinal fusion with or without the use of BMP*

\begin{tabular}{|c|c|c|c|c|}
\hline \multirow[b]{2}{*}{ Complication Type } & \multicolumn{2}{|c|}{ No. of Patients (\%) } & \multirow[b]{2}{*}{ p Value§ } & \multirow[b]{2}{*}{ RR of Complication $(95 \% \mathrm{CI})$} \\
\hline & BMP† & Controlf & & \\
\hline Respiratory & $1,773(1.25)$ & $4,141(1.30)$ & 0.22 & $0.966(0.914-1.021)$ \\
\hline Cardiac & $2,778(1.96)$ & $7,716(2.42)$ & $<0.001$ & $0.812(0.778-0.848)$ \\
\hline Peripheral vascular & $219(0.15)$ & $601(0.19)$ & 0.014 & $0.822(0.704-0.959)$ \\
\hline CNS & $1,110(0.78)$ & $3,799(1.19)$ & $<0.001$ & $0.659(0.617-0.704)$ \\
\hline Deep vein thrombosis & $2,162(1.53)$ & $5,659(1.77)$ & $<0.001$ & $0.862(0.820-0.905)$ \\
\hline Hematoma & $3,540(2.50)$ & $9,054(2.84)$ & $<0.001$ & $0.882(0.849-0.926)$ \\
\hline Hemorrhage during an op & $3,783(2.67)$ & $10,688(3.35)$ & $<0.001$ & $0.798(0.770-0.828)$ \\
\hline Wound (including infection) & $4,977(3.52)$ & $13,884(4.35)$ & $<0.001$ & $0.808(0.783-0.835)$ \\
\hline Mechanical (implant or graft) & $9,367(6.62)$ & $15,952(5.00)$ & $<0.001$ & $1.325(1.292-1.358)$ \\
\hline CSF leak & $12(0.01)$ & $91(0.03)$ & $<0.001$ & $0.297(0.163-0.543)$ \\
\hline Other & $2,005(1.42)$ & $4,212(1.32)$ & $<0.005$ & $1.074(1.019-1.132)$ \\
\hline \multicolumn{5}{|c|}{$\begin{array}{l}\text { * The total number of patients was } 460,773 \text {. } \\
\text { † Percentage is based on all patients in BMP group. } \\
\text { † Percentage is based on all patients in control group. } \\
\text { § Determined using the chi-square test. } \\
\text { ๆ RR for BMP use compared to no BMP use. }\end{array}$} \\
\hline
\end{tabular}




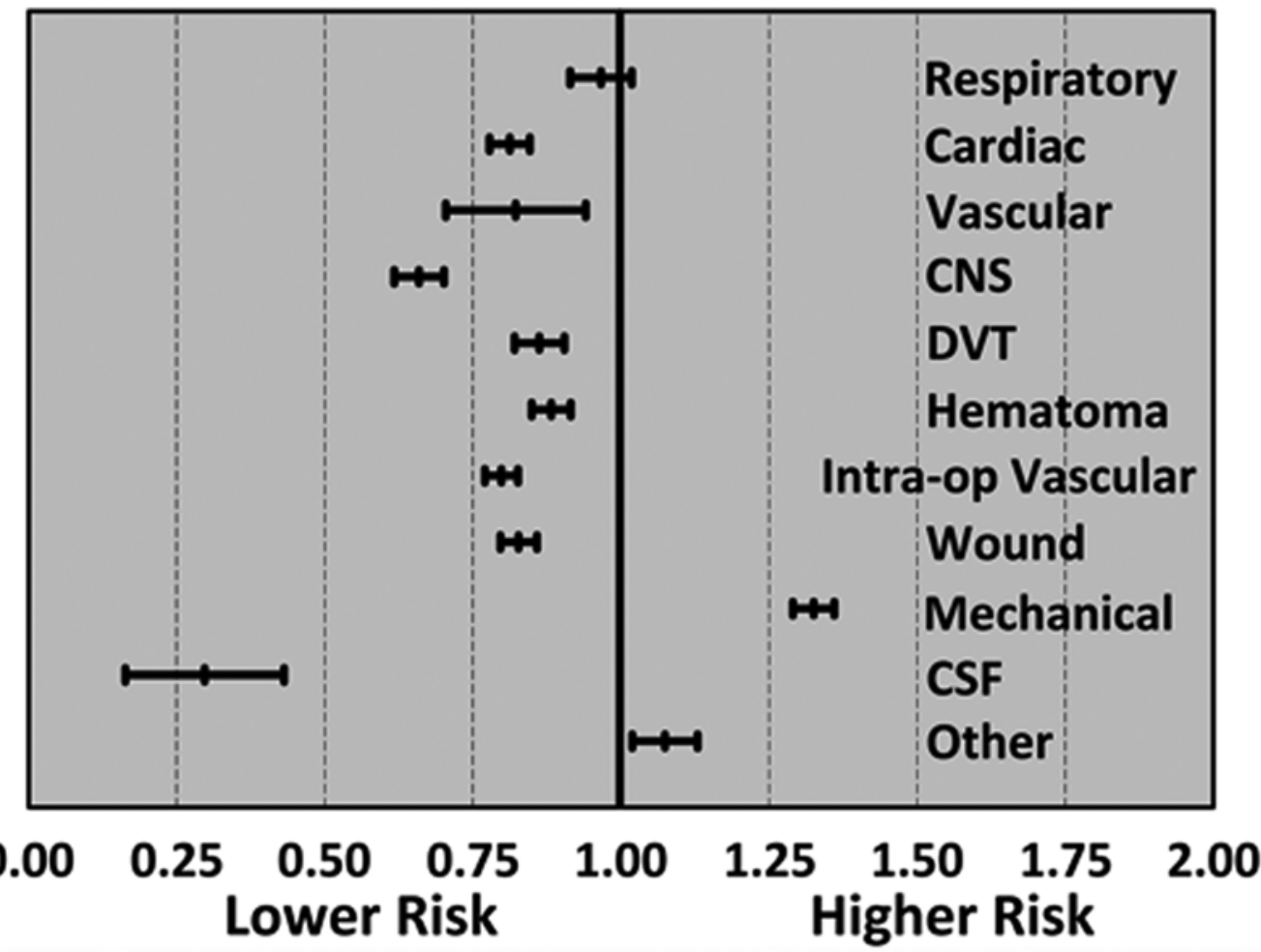

FIG. 1. Forest plot illustrating the RR of developing a complication with the use of BMP compared with no BMP use. A value less than 1 indicates a lower RR associated with BMP use compared with no BMP use.

328,468 patients who underwent spinal fusion procedures, they found that BMP was used in $25 \%$ of all the fusion procedures, which is comparable to the findings of the present study (30.7\%). In regard to lumbar spinal fusion, they found no difference in the postoperative complication rates between the BMP and non-BMP groups $(6.97 \%$ vs $7.18 \%$, respectively; OR 0.96 [CI $0.89-1.05]$ ). Another study, by Williams et al., included 55,862 cases of spinal fusion performed with and those performed without BMP from the Scoliosis Research Society morbidity and mortality database; the authors found no difference in the overall complication rates between the 2 groups $(8.4 \%$ vs $8.5 \%$; $p$ $=0.5$ ). Deyo et al. ${ }^{8}$ more recently reported complications in Medicare patients who underwent spinal fusion between 2003 and 2004. They found no statistical differences in the complication or reoperation rates between the BMP and control groups but discovered that fewer patients in whom BMP was used were discharged to nursing homes. This outcome may have pettily offset increased hospital charges associated with BMP. The results of these 3 studies are comparable to those of our study, which show little difference between treatment groups; however, these other studies all reported much lower overall complication rates.

We believe that our methodology was more comprehensive than those of the aforementioned studies. Their absolute complication rates were determined arbitrarily by the outcome variables or list of ICD-9-CM codes used in the analyses. Our study included a greater number of ICD-9-CM diagnosis codes than the Cahill et al. ${ }^{4}$ study (57 vs 42 codes, respectively). Furthermore, the codes for mechanical complications of implant or graft, which comprised $6.6 \%$ of the BMP group and $5.0 \%$ of the control group, were not included in the Cahill et al. ${ }^{4}$ study. Previous studies reported on early clinical use of BMP close to the FDA approval date in 2002, which initially included mainly on-label applications. We expect the more contemporary complication rates to be increased because of expanded applications to complex and off-label procedures. This reasoning may explain the increased absolute complication rate observed in our study. However, the RRs of complications after both spinal fusion with BMP and spinal fusion without BMP are similar to those in previous studies and support the robust nature of our analysis.

There are several limitations to this study. This was a retrospective review of an administrative database and was subject to the inherent weaknesses of this methodology. ${ }^{18}$ There is no method for determining the completeness of data submission and/or accuracy of reporting, although the use of ICD-9-CM codes theoretically limits the magnitude of this limitation. The results presented here are the minimum rates, and they likely underestimate the true incidences of both complications and reoperations.

There was no documentation of the amount of BMP used in each case, so we cannot comment on whether there is a dose-response relationship associated with complications after the use of BMP in spinal fusion surgery. It is impossible to determine if the reported complications (according to the ICD-9-CM codes) were directly related to the use of BMP or to the complexity of the procedure, patient comorbidities, or other factors. These data do not and cannot address the specific complications associated with BMP recently reported in the literature, such as retrograde ejaculation, heterotopic bone formation, and postoperative radiculitis. $^{5}$ 
Finally, restrictions in the database do not permit multivariate analysis of comorbidity. To control for this limit, we stratified the results according to complication occurrence, sex, and age group and then compared patients who received BMP with patients who did not receive BMP. As expected, the patients in all subgroups who had 1 or more complications had a higher CCI. Patients who underwent spinal fusion without BMP had a higher CCI than patients who received BMP in all subgroups except for females without complications. The statistical significance is likely a result of the large sample size. The clinical significance is minimal, because the CCIs between the groups were generally similar across the sex and age groups.

Despite the disquieting review by Carragee et al., ${ }^{5}$ who reported an increase in the risk of developing postoperative infections with the use of BMP in spinal surgery, the present study and the other reports cited above show that the overall complication rates are similar. From our results we conclude that BMP use does not increase the overall risk of having a postoperative complication after lumbar spinal fusion; however, the use of BMP is associated with a higher risk of reoperation. Surgeons should continue to monitor the use of BMP responsibly; large-scale prospective randomized trials are needed to evaluate the safety profile of this substance.

\section{Acknowledgment}

This project was funded by a grant given by the University of Wisconsin Department of Orthopedics and Rehabilitation.

\section{References}

1. Boakye M, Mummaneni PV, Garrett M, Rodts G, Haid R: Anterior cervical discectomy and fusion involving a polyetheretherketone spacer and bone morphogenetic protein. J Neurosurg Spine 2:521-525, 2005

2. Burkus JK, Gornet MF, Dickman CA, Zdeblick TA: Anterior lumbar interbody fusion using rhBMP-2 with tapered interbody cages. J Spinal Disord Tech 15:337-349, 2002

3. Burkus JK, Sandhu HS, Gornet MF, Longley MC: Use of rhBMP-2 in combination with structural cortical allografts: clinical and radiographic outcomes in anterior lumbar spinal surgery. J Bone Joint Surg Am 87:1205-1212, 2005

4. Cahill KS, Chi JH, Day A, Claus EB: Prevalence, complications, and hospital charges associated with use of bonemorphogenetic proteins in spinal fusion procedures. JAMA 302:58-66, 2009

5. Carragee EJ, Hurwitz EL, Weiner BK: A critical review of recombinant human bone morphogenetic protein-2 trials in spinal surgery: emerging safety concerns and lessons learned. Spine J 11:471-491, 2011

6. Carragee EJ, Mitsunaga KA, Hurwitz EL, Scuderi GJ: Retrograde ejaculation after anterior lumbar interbody fusion using rhBMP-2: a cohort controlled study. Spine J 11:511-516, 2011

7. Crawford CH III, Carreon LY, McGinnis MD, Campbell MJ, Glassman SD: Perioperative complications of recombinant human bone morphogenetic protein- 2 on an absorbable collagen sponge versus iliac crest bone graft for posterior cervical arthrodesis. Spine (Phila Pa 1976) 34:1390-1394, 2009

8. Deyo RA, Ching A, Matsen L, Martin BI, Kreuter W, Jarvik JG, et al: Use of bone morphogenetic proteins in spinal fusion surgery for older adults with lumbar stenosis: trends, complications, repeat surgery, and charges. Spine (Phila Pa 1976) 37:222-230, 2012

9. Dimar JR II, Glassman SD, Burkus JK, Carreon LY: Clinical outcomes and fusion success at 2 years of single-level instrumented posterolateral fusions with recombinant human bone morphogenetic protein-2/compression resistant matrix versus iliac crest bone graft. Spine (Phila Pa 1976) 31:2534-2540, 2006

10. Dimar JR II, Glassman SD, Burkus JK, Pryor PW, Hardacker JW, Carreon LY: Clinical and radiographic analysis of an optimized rhBMP-2 formulation as an autograft replacement in posterolateral lumbar spine arthrodesis. J Bone Joint Surg Am 91:1377-1386, 2009

11. Food and Drug Administration: Summary of Safety and Effectiveness Data for P000058 Medtronic's InFUSE Bone Graft/LT-CAGE Lumbar Tapered Fusion Device. Washington, DC: Food and Drug Administration, 2002

12. Food and Drug Administration Orthopaedic and Rehabilitation Devices Advisory Panel: Executive Summary for P050036 Medtronic's AMPLIFY rhBMP-2 Matrix. Washington, DC: Food and Drug Administration, 2010

13. Glassman SD, Carreon LY, Djurasovic M, Campbell MJ, Puno RM, Johnson JR, et al: RhBMP-2 versus iliac crest bone graft for lumbar spine fusion: a randomized, controlled trial in patients over sixty years of age Efficacy of autologous iliac crest bone graft and bone morphogenetic proteins for posterolateral fusion of lumbar spine: a meta-analysis of the results. Spine (Phila Pa 1976) 33:2843-2849, 2008

14. Haid RW Jr, Branch CL Jr, Alexander JT, Burkus JK: Posterior lumbar interbody fusion using recombinant human bone morphogenetic protein type 2 with cylindrical interbody cages. Spine J 4:527-539, 2004

15. Hiremath GK, Steinmetz MP, Krishnaney AA: Is it safe to use recombinant human bone morphogenetic protein in posterior cervical fusion? Spine (Phila Pa 1976) 34:885-889, 2009

16. Joseph V, Rampersaud YR: Heterotopic bone formation with the use of rhBMP2 in posterior minimal access interbody fusion: a CT analysis. Spine (Phila Pa 1976) 32:2885-2890, 2007

17. Lewandrowski KU, Nanson C, Calderon R: Vertebral osteolysis after posterior interbody lumbar fusion with recombinant human bone morphogenetic protein 2: a report of five cases. Spine J 7:609-614, 2007

18. McCarthy EP, Iezzoni LI, Davis RB, Palmer RH, Cahalane M, Hamel MB, et al: Does clinical evidence support ICD-9$\mathrm{CM}$ diagnosis coding of complications? Med Care 38:868876,2000

19. Meisel HJ, Schnöring M, Hohaus C, Minkus Y, Beier A, Ganey T, et al: Posterior lumbar interbody fusion using rhBMP-2. Eur Spine J 17:1735-1744, 2008

20. Rihn JA, Patel R, Makda J, Hong J, Anderson DG, Vaccaro AR, et al: Complications associated with single-level transforaminal lumbar interbody fusion. Spine J 9:623-629, 2009

21. Schoenfeld AJ, Ochoa LM, Bader JO, Belmont PJ Jr: Risk factors for immediate postoperative complications and mortality following spine surgery: a study of 3475 patients from the National Surgical Quality Improvement Program. J Bone Joint Surg Am 93:1577-1582, 2011

22. Shields LB, Raque GH, Glassman SD, Campbell M, Vitaz T, Harpring J, et al: Adverse effects associated with highdose recombinant human bone morphogenetic protein-2 use in anterior cervical spine fusion. Spine (Phila Pa 1976) 31:542-547, 2006

23. Smoljanovic T, Siric F, Bojanic I: Six-year outcomes of anterior lumbar interbody arthrodesis with use of interbody fusion cages and recombinant human bone morphogenetic protein-2. J Bone Joint Surg Am 92:2614-2616, 2010

24. Smucker JD, Rhee JM, Singh K, Yoon ST, Heller JG: Increased swelling complications associated with off-label usage of rhBMP-2 in the anterior cervical spine. Spine (Phila Pa 1976) 31:2813-2819, 2006 
25. Vaidya R, Sethi A, Bartol S, Jacobson M, Coe C, Craig JG: Complications in the use of rhBMP-2 in PEEK cages for interbody spinal fusions. J Spinal Disord Tech 21:557-562, 2008

26. Vaidya R, Weir R, Sethi A, Meisterling S, Hakeos W, Wybo $\mathrm{CD}$ : Interbody fusion with allograft and rhBMP-2 leads to consistent fusion but early subsidence. J Bone Joint Surg Br 89:342-345, 2007

27. Williams BJ, Smith JS, Fu KM, Hamilton DK, Polly DW Jr, Ames CP, et al: Does bone morphogenetic protein increase the incidence of perioperative complications in spinal fusion? A comparison of 55,862 cases of spinal fusion with and without bone morphogenetic protein. Spine (Phila Pa 1976) 36:1685-1691, 2011

28. Wong DA, Kumar A, Jatana S, Ghiselli G, Wong K: Neurologic impairment from ectopic bone in the lumbar canal: a potential complication of off-label PLIF/TLIF use of bone morphogenetic protein-2 (BMP-2). Spine J 8:1011-1018, 2008

\section{Disclosure}

Dr. Savage is a consultant for Stryker Spine. Mr. Ellison is a consultant for PearlDiver Technologies, Inc.

\section{Author Contributions}

Conception and design: all authors. Acquisition of data: all authors. Analysis and interpretation of data: all authors. Drafting the article: all authors. Critically revising the article: all authors. Reviewed submitted version of manuscript: all authors. Approved the final version of the manuscript on behalf of all authors: Kelly. Statistical analysis: all authors. Administrative/technical/material support: Kelly, Savage, Anderson. Study supervision: Anderson.

\section{Supplemental Information}

Online-Only Content

Supplemental material is available online.

Appendices 1 and 2. http://thejns.org/doi/suppl/2015.7.FOCUS15240.

\section{Correspondence}

Mick P. Kelly, Department of Orthopedics and Rehabilitation, University of Wisconsin School of Medicine and Public Health, UWMF Centennial Bldg., 1685 Highland Ave., 6th Fl., Madison, WI 53705.email: mick.kelly@uwalumni.com. 